\title{
Remaining unconscious: The burden of traumatic brain injuries in India
}

\author{
Deepak Agrawal, P. K. Singh, S. Sinha, D. K. Gupta, G. D. Satyarthee, M. C. Misra ${ }^{1}$ \\ Departments of Neurosurgery, and ${ }^{1}$ Surgery, JPNA Trauma Centre, All India Institute of Medical Sciences, New Delhi, India
}

\begin{abstract}
Introduction: It is well-known that severe traumatic brain injuries (TBI) have a poor outcome. However, what is not well-known is the outcome for those who survive but remain unconscious at the time of discharge from the hospital. Aims and Objectives: To assess the outcome of severe TBI patients who have a motor response of M5 or lower on the Glasgow coma score (GCS) at discharge from a single centre in India. Materials and Methods: In this retrospective study carried at one trauma centre in India, a prospectively maintained neurotrauma registry was queried from May 2010 to February 2013 for patients who had severe traumatic brain injury (GCS $\leq 8)$ at admission and had a motor response of $\mathrm{M}_{5}$ or lower on the GCS at discharge. Demographic and clinical data were analyzed, and outcome Glasgow outcome scale (GOS) assessed at 6 months using a telephonic questionnaire. Observations and Results: There were a total of 1525 patients with severe TBI in the study period. Of these $166(10.9 \%)$ were unconscious (motor response M5 or lower on the GCS) at discharge from the hospital. 139 were males and 27 females with a mean age of 33.9 years. After a mean hospital stay of 24.31 days, the discharge motor score was $\mathrm{M}_{5}$ in 32 (19.3\%), M4 in 44 (26.5\%), M3 in 59 $(35.5 \%), \mathrm{M}_{2}$ in $44(26.5 \%)$, and $\mathrm{M}_{1}$ in $9(5.4 \%)$. Telephonic follow-up was available in $102(61.4 \%)$ of the patients. 54 (52.9\%) patients had died and $32(31.4 \%)$ remained unconscious (vegetative) at 6 months. Only 16 patients (15.7\%) had a good outcome (GOS 1-2) at 6 months following an injury. Conclusions: This is the only study of its kind on patients who remain unconscious at discharge following severe TBI and reveals that around $50 \%$ will die and another $30 \%$ remains vegetative at 6 months of discharge. Only a small percentage ( $15 \%$ in our study) will become conscious and partially integrated in the society.
\end{abstract}

Key words: Head injury, mortality, outcome, severe traumatic brain injuries, unconscious, vegetative

\section{Introduction}

Worldwide, head injury is the single largest cause of death and disability following an injury..$^{[1]}$ Most head injuries are due to roadside accidents. ${ }^{[2]}$ The burden of head injury is greatest in low- and middle-income countries (LAMIC), where $85 \%$ of the world's population live. ${ }^{[3]}$ The World Health Organization estimates that almost $90 \%$ of deaths due to injuries occur in these settings. ${ }^{[1]}$ Head Injury is the leading cause of disability in people under 40, severely disabling 150-200 people per million annually. ${ }^{[4,5]}$ In 2005, road traffic injuries resulted

\begin{tabular}{|l|l|}
\hline \multicolumn{2}{|c|}{ Access this article online } \\
\hline Quick Response Code: & Website: \\
\hline & www.ruralneuropractice.com \\
\hline & \\
\hline
\end{tabular}

in the death of an estimated 110,000 persons, 2.5 million hospitalizations, 8-9 million minor injuries and economic losses to the tune of $3 \%$ of the gross domestic product in India. ${ }^{[6]}$ The accident rate of 35/1000 vehicles in India is also amongst the highest in the world. ${ }^{[7]}$

However, resources have not been diverted adequately by governments toward prevention, management and rehabilitation of head injuries in LAMIC such as India. Most patients with severe traumatic brain injuries (TBI) in developing countries are discharged to home-based care due to lack of rehabilitative facilities and health insurance. Those patients who are discharged in an unconscious state are particularly difficult to manage at home and are prone to decubitus ulcers, respiratory infections, inadequate nutrition, and physiotherapy. However, data is lacking on the actual load of vegetative patients and their outcomes, especially from developing countries.

Patients, who remain unresponsive to the environment even though their eyes may be open, are considered to

\section{Address for correspondence:}

Dr. Deepak Agrawal, Department of Neurosurgery, JPNA Trauma Centre, All India Institute of Medical Sciences, New Delhi - 110029 , India. E-mail: drdeepak@gmail.com 
be in a vegetative state (VS). ${ }^{[8,9]}$ A persistent VS has been defined as a VS still present 1 month after acute traumatic or nontraumatic brain damage..$^{[10,11]}$ As by definition, VS requires a minimum period of 1 month of remaining unconscious, most patients who remain unconscious are not labeled as vegetative at discharge. However, there are no studies assessing conversion to VS, specifically in this group of patients.

\section{Materials and Methods}

In this retrospective study carried at one trauma center in India, a prospectively maintained neurotrauma registry was queried from May 2010 to February 2013 for patients who had severe traumatic brain injury Glasgow coma score (GCS $\leq 8)$ at admission and had a motor response of M5 or lower on the GCS at discharge. Ethics approval was taken prior to conducting the study. Unconsciousness was described as patients with a motor score of M5 or lower on the GCS irrespective of the verbal (V) or eye (E) response. Patients who were suspected to have dysphasia were excluded from the study. Demographic and clinical data was analyzed, and outcome assessed at 6 months after injury using a telephonic questionnaire. The questions asked were: (1) Is the patient alive? (2) If alive, is the patient responding to commands (conscious)? (3) If the patient is conscious, is he able to perform activities of daily living like feeding himself, going to toilet independently and going to preinjury occupation?

If the family members replied that patient had gone back to preinjury occupation it was considered as Glasgow outcome scale (GOS) 1, If patient was able to perform activities of daily living, but not able to go back to work it was considered as GOS 2, If patient was conscious but not able to do activities of daily living, it was considered as GOS 3. If a patient remained unconscious, it was GOS 4 and if the patient had died it was GOS 5. GOS 1-3 was considered as the unfavorable outcome and GOS 4-5 was considered as a good outcome.

\section{Observations and Results}

There were a total of 1525 patients with severe TBI in the study period. Of these $166(10.9 \%)$ were unconscious (motor response M5 on the GCS or lower) at discharge from the hospital. 139 were males and 27 females with a mean age of 33.9 years. Average hospital stay was 24.31 days (range: 8-64 days) and was 16.71 days for M5, 20.63 days for M4, 26.33 days for M3, 30.59 days for M2 and 16.3 days for M1 patients [Table 1].
Table 1: Mortality and outcome at 6 months with respect to motor scores at the time of discharge

\begin{tabular}{lccccc}
\hline N=112 & Total & Death & $\begin{array}{c}\text { Lost on } \\
\text { follow up }\end{array}$ & Favorable & Unfavorable \\
\hline M1 & 9 & 4 & 5 & 0 & 4 \\
M2 & 44 & 15 & 12 & 3 & 29 \\
M3 & 59 & 26 & 24 & 2 & 33 \\
M4 & 22 & 4 & 11 & 3 & 8 \\
M5 & 32 & 5 & 12 & 8 & 12 \\
& 166 & 54 & 64 & 16 & 86 \\
\hline
\end{tabular}

The discharge motor score was M5 in 32 (19.3\%), M4 in 44 (26.5\%), M3 in 59 (35.5\%), M2 in 44 (26.5\%) and M1 in 9 (5.4\%). Telephonic follow-up was available in 102 (61.4\%) of the patients. $54(52.9 \%)$ patients had died and 32 $(31.4 \%)$ remained unconscious (vegetative) at 6 months. $100 \%$ of M1, $90.6 \%$ of M2, $94.3 \%$ of M3, $72.2 \%$ of M4, and $60 \%$ of M5 patients had an unfavorable outcome at 6 months. Only 16 patients (15.7\%) had a good outcome (GOS 1-2) at 6 months post injury.

\section{Discussion}

Incidence, as well as the severity of head injuries, the, is rising in developing countries due to rapid industrialization with a lag in legal, healthcare, and safety reforms. Delhi with a population of around 15 million has the dubious distinction of having the largest number of road traffic accidents of any city in India. The enormity of burden can be assessed by the fact that our study had more than 1500 severe head injured patients in $<3$ years and was conducted at only one hospital! One of the reasons for the step-motherly attitude by policy makers toward head injury prevention, management, and rehabilitation, is the lack of hard statistics of the actual burden of disease which head injuries carry.

In spite of the improvement in care for head injured patients, there has not been a marked decline in the mortality rates for severe head injuries. Kagan and Baker found that mortality rates were between $26.7 \%$ and $41.4 \%$ for severe TBI patients in Level 1 trauma centers. ${ }^{[12]}$ Fakhry et al. in their study found $28.8 \%$ mortality rate of severe TBI patients. ${ }^{[13]}$ It has also been shown that developing (low and middle income) countries have a pooled mortality rate of $51 \%$ for severe TBI as compared to $30 \%$ for high-income countries.$^{[3]}$ Nevertheless, in-hospital mortality tells only part of the story on the outcome of these patients. Six months outcome is often poorer due to lack of rehabilitative care and facilities, especially in developing countries. Most of the patients are discharged to home-based rehabilitation with tracheostomy and oro-gastric tube in 
situ. In our center, unconscious patients with severe TBI are discharged with tracheostomy tube in situ after ensuring that patient can maintain oxygen saturation on room air and after training relatives regarding care of tracheostomy tube, suctioning, and home-based rehabilitation. This reflects the pressure on beds in our institution.

Interestingly, however, there are no studies on the outcome of patients who are discharged from the acute care facility in this unconscious state. Furthermore, a significant number (10.9\% in our study) are discharged in the unconscious state. As all studies are based on admission GCS, it is also often not possible to assess how many patients remained unconscious at the time of discharge and became vegetative at 6 months. The outcomes of these patients have also not been studied properly. In our study, patients with M2 motor response had the longest hospital duration with unfavorable outcome occurring in $90 \%$ of these patients at 6 months.

GCS has remained a robust scale for assessment and prognostication in TBI and the motor score (M response) continues to have the highest predictive value within the GCS. We, therefore, decided to use motor response as criteria to differentiate unconscious and conscious patients. It may be sometimes difficult to differentiate unconsciousness from dysphasia as both disease states may show a motor response of 5 . However, left sided contusion in the posterior frontal and/or temporal regions along with the presence of gaze fixation are clues towards dysphasia. We excluded any patient with suspected dysphasia in our study.

Our study had a reasonable follow-up of $61.4 \%$ of the patients at 6 months and showed the poor outcomes in this subgroup of patients. $54(52.9 \%)$ patients (who were unconscious at discharge) had died and 32 (31.4\%) remained unconscious (vegetative) at 6 months with only 16 patients (15.7\%) having good outcome (GOS 1-2) at 6 months. This study also shows that the majority of the patients (nearly $85 \%$ ) who are discharged in an unconscious state will either die or become vegetative.

\section{Conclusions}

This is the only study of its kind on patients who remain unconscious at discharge following severe TBI and reveals that around 50\% will die, and another 30\% become vegetative within 6 months of discharge. Only a small percentage will become conscious and partially independent in the society.

\section{References}

1. Murray CJ, Lopez AD. Global mortality, disability, and the contribution of risk factors: Global Burden of Disease Study. Lancet 1997;349:1436-42.

2. Rajendra PB, Mathew TP, Agrawal A, Sabharawal G. Characteristics of associated craniofacial trauma in patients with head injuries: An experience with 100 cases. J Emerg Trauma Shock 2009;2:89-94.

3. De Silva MJ, Roberts I, Perel P, Edwards P, Kenward MG, Fernandes J, et al. Patient outcome after traumatic brain injury in high-, middle- and low-income countries: Analysis of data on 8927 patients in 46 countries. Int J Epidemiol 2009;38:452-8.

4. Fleminger $\mathrm{S}$, Ponsford J. Long term outcome after traumatic brain injury. BMJ 2005;331:1419-20.

5. Bruns J Jr, Hauser WA. The epidemiology of traumatic brain injury: A review. Epilepsia 2003;44 Suppl 10:2-10.

6. Gururaj G. Road traffic deaths, injuries and disabilities in India: Current scenario. Natl Med J India 2008;21:14-20.

7. Dandona R, Kumar GA, Ameer MA, Ahmed GM, Dandona L. Incidence and burden of road traffic injuries in urban India. Inj Prev 2008;14:354-9.

8. Jennett B, Plum F. Persistent vegetative state after brain damage. A syndrome in search of a name. Lancet 1972;1:734-7.

9. Laureys S, Boly M. The changing spectrum of coma. Nat Clin Pract Neurol 2008;4:544-6.

10. Laureys S, Owen AM, Schiff ND. Brain function in coma, vegetative state, and related disorders. Lancet Neurol 2004;3:537-46.

11. The vegetative state: Guidance on diagnosis and management. Clin Med 2003;3:249-54.

12. Kagan RJ, Baker RJ. The impact of the volume of neurotrauma experience on mortality after head injury. Am Surg 1994;60:394-400.

13. Fakhry SM, Trask AL, Waller MA, Watts DD, IRTC Neurotrauma Task Force. Management of brain-injured patients by an evidence-based medicine protocol improves outcomes and decreases hospital charges. J Trauma 2004;56:492-9.

How to cite this article: Agrawal D, Singh PK, Sinha S, Gupta DK, Satyarthee GD, Misra MC. Remaining unconscious: The burden of traumatic brain injuries in India. J Neurosci Rural Pract 2015;6:520-2.

Source of Support: Nil. Conflict of Interest: None declared. 